International Journal of Health Sciences
Available online at www.sciencescholar.us
Vol. 6 No. 1, April 2022, pages: 244-254
e-ISSN: 2550-696X, p-ISSN: 2550-6978
https://doi.org/10.53730/ijhs.v6n1.3907

\title{
Education of Humanitarian Specialists during COVID-19 Pandemic
}

\author{
(1) CrossMark \\ Nadiia Marynets a, Hanna Marynchenko ${ }^{\text {b }}$, Renata Vynnychuk ${ }^{c}$, Halyna Voloshchuk ${ }^{d}$, \\ Tatiana Voropayeva ${ }^{\mathrm{e}}$
}

Manuscript submitted: 15 September 2021, Manuscript revised: 12 December 2021, Accepted for publication: 9 January 2022

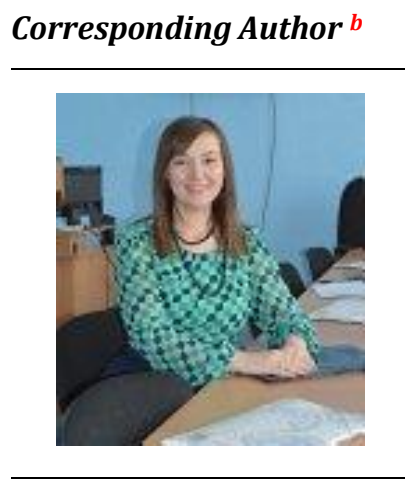

Keywords

COVID-19;

health preservation;

mental health;

pandemic;

special education;

video conferencing;

virtual learning;

\begin{abstract}
The study aims to consider the components of the mixed type of education organization within the humanitarian fields of study; to establish the students' assessment of the mixed type of education. The research methodology is based on a comprehensive approach, the method of pedagogical experiment, statistical methods are taken to work, descriptive method. The research hypothesis lies in the fact that adaptation to a blended education includes the use of software, social networking platform, tools of informal humanitarian education with open access in combination with face-to-face education, and the acquisition of practical experience, which is difficult to obtain virtually. The research result involves establishing the effectiveness of mixed forms of education using digital technology capabilities as a comprehensive humanitarian specialist. In the future, there should be continued the following steps: to conduct several experiments to solve the problem of training humanitarian specialists during the pandemic era, the study of the right balance between learning at home and at university, where the main thing is to maintain readiness to professional activities, reducing increased anxiety and avoiding professional burnout, which has become a big educational problem during the quarantine times.
\end{abstract}

International Journal of Health Sciences (C) 2022. This is an open access article under the CC BY-NC-ND license (https://creativecommons.org/licenses/by-nc-nd/4.0/).

\section{Contents}

Abstract.

1 Introduction.

\footnotetext{
a Ferenc Rákóczi II Transcarpathian Hungarian College of Higher Education, Beregszász, Ukraine

b V.O. Sukhomlynskyi National University of Mykolaiv, Mykolaiv, Ukraine

c Poltava V.G. Korolenko National Pedagogical University, Poltava, Ukraine

d Vasyl Stefanyk Precarpathian National University, Kherson, Ukraine

e Taras Shevchenko National University of Kyiv, Kyiv, Ukraine
} 


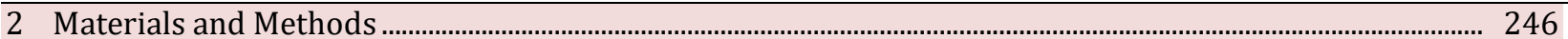

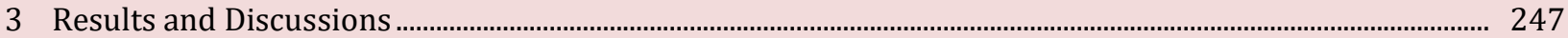

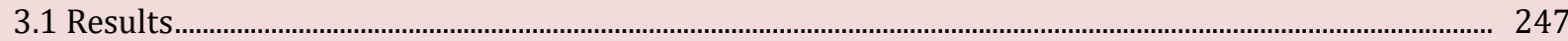

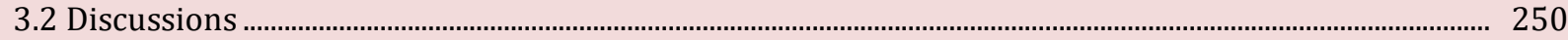

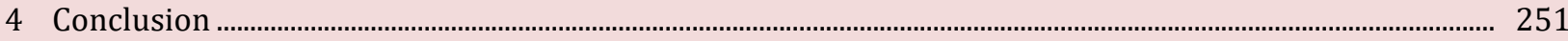

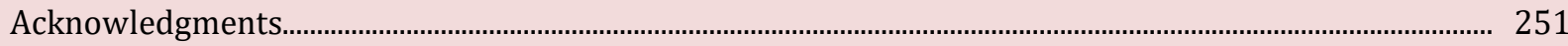

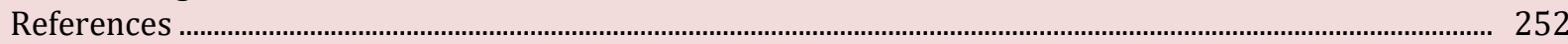

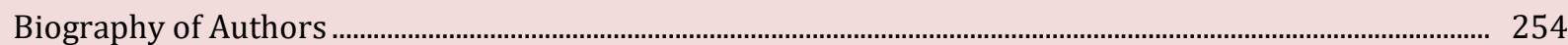

\section{Introduction}

Reorganization of the educational modern reality of university education. It is also relevant to the humanitarian sector. Preservation of the qualitative specialists' training in this educational paradigm is rooted in the search for a harmonious combination of online and traditional learning. As well, such a problem is interesting and relevant for the research, although the studies of such a wide problem range have a different direction (Riva et al., 2021).

First of all, the benefits of online learning, which has significantly increased in higher education due to the Coronavirus pandemic, are considered. The researchers Cortese et al. (2020), name cost-effectiveness (conveniently saves on travel, housing); wide accessibility (activation of informal education, open access to online learning platforms, cheaper educational services); health preservation (lack of interpersonal contact prevents morbidity). However, distance education and learning conditions caused by quarantine restrictions also bring several risks and difficulties. Several studies show the problems of stressful situations, anxiety, and emotional burnout growth, the lack of social interaction, group cooperation, weak motivation of education applicants (Singh et al., 2020). In addition, the problem of technological illiteracy, lack of necessary technical support, Internet communication, etc., should be mentioned (Al Azzam et al., 2021). A separate topic turned out to be time management and cultural and national characteristics of the students under quarantine conditions (Gallagher \& Schleyer, 2020; Mukhtar et al., 2022). This, in a certain way, forms the scientific problematics as the actualization of a deep and comprehensive study of not only the distance learning phenomenon, a forced educational and didactic-methodological form, but one that, above all, is an educational innovation, a form of human cognitive activity manifestation, the result of the educational civilizational development. Separate research interest should dwell on the HEIs development results in the context of quality and efficiency of interaction in social, natural, and technical learning (Kliuchnyk et al., 2021).

The transition period from traditional forms of education to online learning, innovations in the distance, and blended education entail a certain educational and ideological crisis. The unpreparedness for such a transition is due to cultural, social, education standards, and long-standing traditions of university education of the past. The exit from the state of stress, which arises when confronted with the unknown, uncertainty, involves acquiring new forms and methods that allow in quarantine to realize the professional needs of future humanitarian specialists. The research in this direction is one of the priorities and also takes place in the context of the search for forms and methods of improving the educational process, which should take into account the effectiveness and level of students' attendance during mixed education form (Palmer et al., 2006; Mattison et al., 2002; Powers et al., 2012). This study aims to consider the components of blended and fulltime learning methods and forms within humanitarian specialties and to establish the level of students' appreciation of a blended education during the COVID-19 pandemic:

- To establish level attendance in full-time and blended education;

- To compare the potential use of methods and forms of learning in blended and traditional education forms;

- To indicate students' evaluation of the constituent methods and form of the educational process in blended learning conditions.

Marynets, N., Marynchenko, H., Vynnychuk, R., Voloshchuk, H., \& Voropayeva, T. (2022). Education of humanitarian specialists during COVID-19 pandemic. International Journal of Health Sciences, 6(1), 244-254. https://doi.org/10.53730/ijhs.v6n1.3907 


\section{Literature review}

Many researchers, following the strategy developed by the European Commission (European Commission, 2019; The Future of Jobs Report WEF, 2020), worked on several studies to improve the higher education quality in Europe. This direction identified one of the crucial learning characteristics during the COVID-19 pandemic, which is education realized under crisis and stressful conditions (Dzvinchuk et al., 2020).

One of the research standpoints is the thesis that university education should maintain an active motivational approach towards students (Bayram-Jacobs, 2015). First of all, it is about adapting to blended learning; it requires a change in the perception of the learning process of all participants. The main thing becomes the readiness for change, awareness of innovative teaching methods and technical means, social and administrative support (Hoofman \& Secord, 2021; Widana et al., 2021).

This dramatic change in the educational paradigm requires changes in the learning forms within the methodology and educational process management (Cuaton, 2020; Zhernova, 2018). A wide range of educational problems that arose during the COVID-19 pandemic is analyzed separately, namely: an assessment of medical education itself, which had to be most restructured, to maintain a practice-centered approach in training the next generation of doctors (Rose, 2020); the problems of learning foreign languages, the success of implementing changes in methodology, appeal to new technological opportunities (Kostikova et al., 2019); also considered the impact on the mental health of education applicants and stresses that led to quarantine restrictions (Van de Groep et al., 2020).

The changes in higher education caused by the COVID-19 pandemic and the need to move to blended learning are seen as an experience with positive and negative traits (Cortese et al., 2020). The positive distance learning traits are the possibility of self-organization, free choice of learning rhythm (Attardi et al., 2021), focus on interactive methods and virtual learning (Anghel, 2020), analyzed ways to find funding for new projects, courses, and learning platforms aimed at educational implementation during the COVID-19 pandemic (Lee et al., 2001; Al-Azzam et al., 2020).

\section{Materials and Methods}

The proposed study is based on a comprehensive approach to the methodology and is in line with similar experimental studies close to the experimental methodology and topics (Boghian, 2019; Synorub \& Medynska, 2019). The method of pedagogical experiment, the method of questioning and observation, statistical method were used; descriptive method, methods of analysis, and synthesis were used to describe the theoretical and methodological foundations of the research.

The main method is the pedagogical experiment; the survey is also involved, as a way to monitor students' opinions on the changes in the forms and methods of educational practices during the education of humanitarian specialists during the COVID-19 pandemic. It also allows us to determine the fact of blended learning as a pedagogical phenomenon and a systemic change in modern university education (Kaparounaki et al., 2020; Cao et al., 2020).

The experiment was introduced during the 2020-2021 academic year (September 2020 - June 2021) at the Kharkiv State Academy of Culture (Ukraine) for students of the Cultural Studies Department (1 group - 28 people) and Kamyanets-Podilsky National University named after Ivan Ohienko (Ukraine) among students of History (1 group - 30 people) and Foreign Philology Departments (1 group - 32 people).

The selection consisted of 60 students of the second year of study of the first (bachelor's) education level. All respondents were combined into 3 groups. All groups had several similar academic disciplines ("History of Ukraine", "Fundamentals of Cultural Studies", "History of European Culture", "Foreign Language", etc.), similar in content aspects of specialties and professional needs.

The survey was conducted with the help of Google Drive forms. The survey process took place at the final stage of the study, constantly (throughout the school year) monitoring the level of student attendance. Formation of curricula, their changes, forms, and methods of training on the course was adjusted taking into account the opinion of education applicants and teachers.

Pre-survey questionnaires were filled out with the respondents' permission, who voluntarily agreed to participate in the survey. The research team adhered to the ethical principles of the study throughout the 
experience. The research data collected through questionnaires assumed the dignity and confidentiality of the participants in the experiment. The surveys were of a survey nature that contained no non-invasive activities. There were no activities that affected the frankness and honesty of the respondents, and the respondents' interests were not violated.

The questionnaires, created for the research purpose, were aligned with the list of new program skills established for the New European University Education (European Commission, 2019).

The research was conducted in 3 stages. Stages I and II included ongoing monitoring of full-time and blended learning students' attendance. Stage 1: Preliminary preparation of participants of the educational process and technical facilities at the university for the new learning conditions during the pandemic. The focus on the blended learning measures implementation also involved the preparation of teaching materials, control questions, and tests for the exam. There is also the selection of innovative methods in an online education environment, which should be in harmony with the lectures introduced face-to-face.

Stage II. End of the first semester during the experiment, the middle of an experiment. Monitoring of students' attendance who changed quarantine conditions, changes in attendance of face-to-face and blended learning. Stage III. Determining the final positions in the new techniques, components, and forms of blended education assessment, which were formed under pandemic conditions at the end of the 2020/2021 academic year. Shortcomings and difficulties observed during the experiment: significant time spending is required (during the academic year - 2 semesters); it is impossible to determine the causes of changes in the evaluations of selected respondents; there is no possibility to implement qualitative and extensive research.

\section{Results and Discussions}

\subsection{Results}

At the 1st stage of the experiment, during the implementation of the blended learning principles, the research team identified changes in the structure and content of the learning process, highlighting several characteristics (Slipchuk et al., 2021). After adopting the curriculum and teaching materials, several pieces of training from specialists-technicians for all respondents on the necessary technical knowledge for video conferencing, classes on educational platforms, participation in non-formal education, and scientific activities and training initiatives (Candarli \& Yuksel, 2012; Viswanathan et al., 2020). The institutions' administration has established standards and rules for evaluating students with the opportunity to take an exam online, credit for the achievements of non-formal education, participation in online conferences, etc.

Marynets, N., Marynchenko, H., Vynnychuk, R., Voloshchuk, H., \& Voropayeva, T. (2022). Education of humanitarian specialists during COVID-19 pandemic. International Journal of Health Sciences, 6(1), 244-254. 


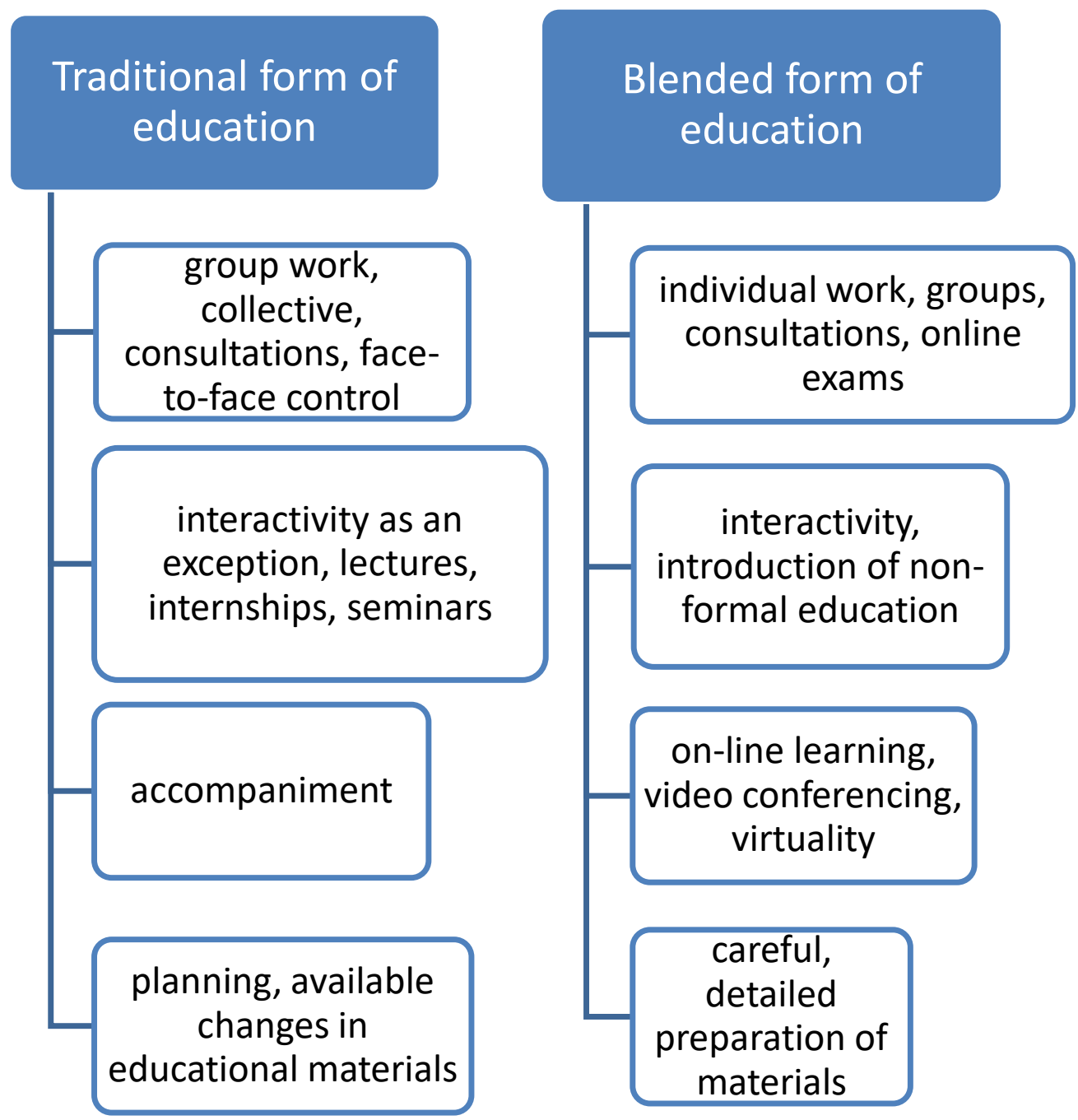

Figure 1. Changes in the methodology of foreign language teaching as a result of the introduction of distance education tools (author's elaboration)

During the pedagogical experiment at the I and II stages, students' attendance was monitored. All classes were conducted in a blended form. Part of them (lecture forms) were conducted face-to-face. The research team estimated how attendance occurred in blended learning in general and how it continued during face-to-face classes. 


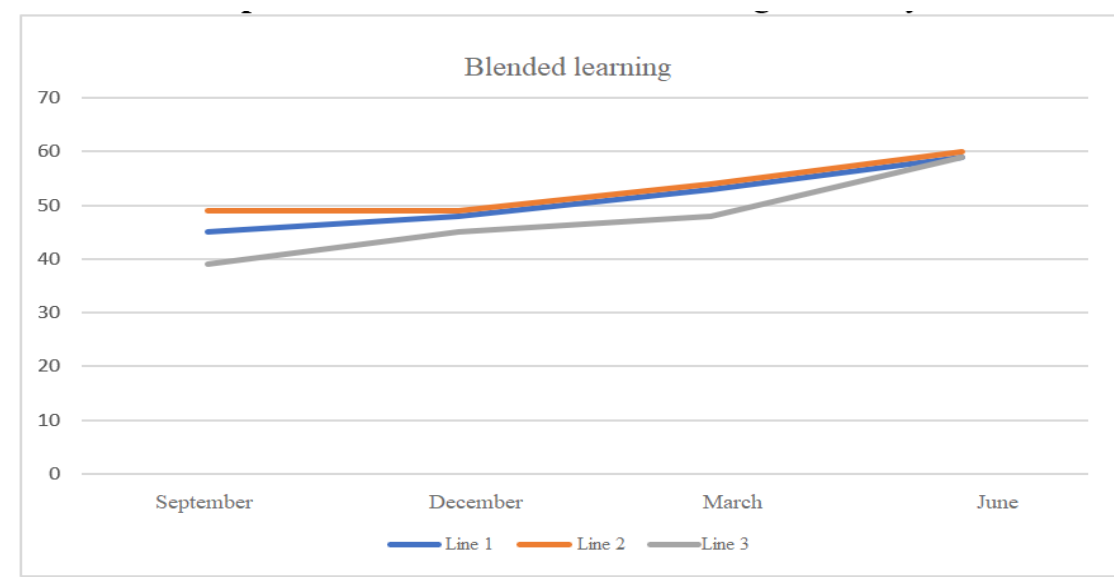

Figure 2. Attendance of blended learning classes by students

As shown in the attendance schedule, it happened in all groups regularly, equally throughout the school year. The lowest attendance rate was observed in all groups at the beginning of the educational process. Then, at the end of the academic year in June, all groups achieved maximum attendance.

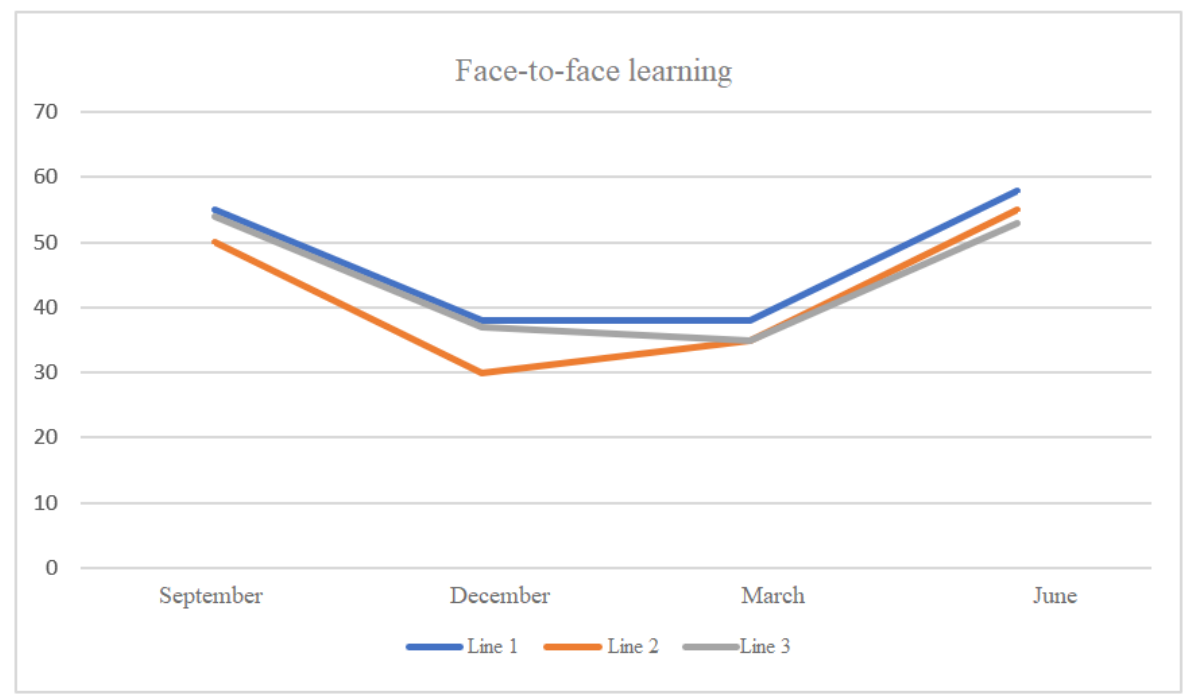

Graph 3. Students' attendance of online learning classes

As we can see, the training part that took place offline (face-to-face form), has a sharp decline in attendance during December and March. This is the time of quarantine restrictions intensification and increase in the number of sick people, which caused the whole group had to go to quarantine and did not attend direct contact classes and did not have the opportunity to attend lectures. Such a group joined the online lectures at the conference-platform level for communication.

At the final III stage, a students' survey was conducted on their assessment of the quality and usefulness of the forms, methods that make up the educational process of learning under COVID-19 pandemic conditions. Students were asked to evaluate the most successful (out of those proposed in the questionnaire) forms, methods, components of blended learning.

Marynets, N., Marynchenko, H., Vynnychuk, R., Voloshchuk, H., \& Voropayeva, T. (2022). Education of humanitarian specialists during COVID-19 pandemic. International Journal of Health Sciences, 6(1), 244-254. https://doi.org/10.53730/ijhs.v6n1.3907 
Table 1

Students' assessment of the educational process components under blended learning conditions (in \%, author's elaboration)

\begin{tabular}{lllll}
\hline № & Preferences & Yes & No & Not sure \\
\hline 1 & Videoconferences & 44 & 50 & 6 \\
2 & Informal education & 57 & 15 & 28 \\
3 & Face-to-face communication in class & 68 & 22 & 10 \\
4 & Creative projects & 50 & 34 & 16 \\
5 & Group work & 45 & 35 & 20 \\
6 & Unbiased assessments & 48 & 25 & 27 \\
7 & Online exams & 36 & 36 & 28 \\
\hline
\end{tabular}

According to the results, the students most positively assessed the non-formal education activities (57\%), face-to-face communication in the classroom (68\%), the opportunity to carry out creative projects $(50 \%$ approval). However, $28 \%$ of the students have not used the opportunities of non-formal education, and $25 \%$ of them have not seen any unbiased assessment. It shows the need to continue active work on the students' adaptation COVID-19 pandemic conditions.

\subsection{Discussions}

The researches of recent years, which, incidentally, are comprehensive ones, have produced several studies that focus on highlighting differences in the learning modes among U.S. (Oster et al., 2021). The calculations from September 2020 to April 2021 showed that there is a problem in providing full-time education to applicants, especially Hispanic students (35.9\% to 58.9\%) and non-Hispanic African American students (32.3\% to 63.4\%). These are alarming percentages, so the authors suggest some recommendations for increasing community access to education should be, first, to address the optimal forms of education for safety (Diachenko et al., 2021).

Our research presents blended learning as one way to improve applicants' access to educational resources in a pandemic environment. According to the research results, blended learning allowed $44(73 \%)$ to 56 $(92 \%)$ of the 60 students to attend classes, but 34 (51\%) of the 60 students were able to attend face-to-face classes between December and March. That is related specifically to quarantine restrictions and morbidity in the study groups. That is why it is necessary to turn to alternative mixed education forms, which would allow quality education in the current pandemic conditions.

Several studies in pedagogy give a defining role to the approval and motivation of educational applicants to new learning forms (Chatterton \& Goddard, 2000), because a significant learning is the lack of access to educational resources for applicants, so the use of distant education forms are actively promoted through their accessibility and effectiveness in parallel with the active implementation of psychological and pedagogical training of educational participants (Synorub \& Medynska, 2019). As our study showed, among the possibilities of change in modern university education, the appeal to video conferencing, social networks, and learning platforms is positively evaluated by respondents, where the most positive result was the nonformal education $(57 \%)$ and the organization of creative projects $(50 \%)$ of respondents. Success in this context is interpreted by the degree of involvement of students in new forms of learning and innovation, advanced in this context, and are ways of harmonious combination of all possible ways of educational communication (Bui et al., 2020; Ernawati et al., 2022).

Given the significant changes in the training of humanitarian specialists caused by the pandemic and, as a result, the significant digitalization of education, administrators HEIs should constantly monitor the level of student satisfaction with the effectiveness of the education provided, assessment of applicants used methods and thus influence the formation of the development strategy of universities (Kuzmina, 2020; Rababah, 2020). This study also presents the results of the survey, which contains the evaluation of those forms and methods of teaching that were used during the introduction of blended education for humanitarian students, the approving attitude towards the forms and methods of blended education was presented by more than $50 \%$ of the respondents. With the pandemic and increased interest in the introduction of distance learning, in our 
opinion, HEIs should be a unique educational environment, allowing future professionals in the humanitarian industry to realize their creative potential and take advantage of the achievements of technological education.

\section{Conclusion}

Under the uncertainty of the pandemic, we can be sure that humanitarian education has changed forever, never to return to its former forms and methods of not only teaching but also administration. Both undergraduate and graduate levels required students and faculty to learn from a distance, with the desire for quality education and professional training not left educational circles.

The new educational culture is only its formation, but the COVID-19 pandemic was the catalyst that launched the transformation process in full force. However, several problems arise in the space of humanitarian education due to the uncertainty of the situation around the organization of the educational process, the state of stress, and the psychophysical tension of students as well as teachers and administration. Such problems can be solved by optimal use of the potential of blended learning in a quarantined environment: virtual tools, practical studios, project activities, and independent work, where all participants of the educational process are involved.

On average, 53\% of the respondents approved of blended learning and its components. The most acceptable was non-formal education (57\%), as well as the importance of face-to-face communication in class $(68 \%)$, identified by students. It demonstrates the success of the introduction of blended learning measures in the humanitarian field and provides an opportunity to move in this direction in the future. The main task of training humanitarian specialists is to provide an effective and high-quality humanitarian education to train the next generation of professionals. The COVID-19 pandemic created an unexpected opportunity for educators to actively promote innovation in the humanitarian field.

Acknowledgments

We are grateful to two anonymous reviewers for their valuable comments on the earlier version of this paper.

Marynets, N., Marynchenko, H., Vynnychuk, R., Voloshchuk, H., \& Voropayeva, T. (2022). Education of humanitarian specialists during COVID-19 pandemic. International Journal of Health Sciences, 6(1), 244-254. 


\section{References}

AlAzzam, M., Abuhammad, S., Abdalrahim, A., \& Hamdan-Mansour, A. M. (2021). Predictors of depression and anxiety among senior high school students during COVID-19 pandemic: The context of home quarantine and online education. The Journal of School Nursing, 37(4), 241-248.

Al-Azzam, N., Elsalem, L., \& Gombedza, F. (2020). A cross-sectional study to determine factors affecting dental and medical students' preference for virtual learning during the COVID-19 outbreak. Heliyon, 6(12), e05704. https://doi.org/10.1016/j.heliyon.2020.e05704

Anghel, D. (2020). Challenges of Homeschooling in Romania during Pandemic Times. Revista Românească pentru Educație Multidimensională, 12(2supl1), 1-11.

Attardi, S. M., Harmon, D. J., Barremkala, M., Bentley, D. C., Brown, K. M., Dennis, J. F., ... \& Farkas, G. J. (2021). An Analysis of Anatomy Education Before and During Covid-19: August-December 2020. Anatomical Sciences Education.

Bayram-Jacobs, D. (2015). RRI: What is it? How to integrate in Science Education. In International Congress on Education for the Future: Issues and Challenges. Retrieved from https://www. researchgate. net/publication/279204567_RRI_What_is_it_How_to_Integrate_in_Science Education.

Boghian, I. (2019). Empowering Teachers to Deal with Classroom Diversity. Romanian Journal for Multidimensional Education/Revista Romaneasca pentru Educatie Multidimensionala, 11(3).

Bui, T. H., Luong, D. H., Nguyen, X. A., Nguyen, H. L., \& Ngo, T. T. (2020). Impact of female students' perceptions on behavioral intention to use video conferencing tools in COVID-19: Data of Vietnam. Data in Brief, 32, 106142. https://doi.org/10.1016/j.dib.2020.106142

Candarli, D., \& Yuksel, H. G. (2012). Students' perceptions of video-conferencing in the classrooms in higher $\begin{array}{llll}\text { education. Procedia-Social and Behavioral 357-361. } & \text { Sciences, 47, }\end{array}$ https://doi.org/10.1016/j.sbspro.2012.06.663

Cao, W., Fang, Z., Hou, G., Han, M., Xu, X., Dong, J., \& Zheng, J. (2020). The psychological impact of the COVID-19 epidemic on college students in China. Psychiatry research, 287, 112934. https://doi.org/10.1016/j.psychres.2020.112934

Chatterton, P., \& Goddard, J. (2000). The response of higher education institutions to regional needs. European Journal of Education, 35(4), 475-496.

Cortese, S., Asherson, P., Sonuga-Barke, E., Banaschewski, T., Brandeis, D., Buitelaar, J., ... \& Simonoff, E. (2020). ADHD management during the COVID-19 pandemic: guidance from the European ADHD Guidelines Group. The Lancet Child \& Adolescent Health, 4(6), 412-414.

Cuaton, G. P. (2020). Philippines higher education institutions in the time of COVID-19 pandemic. Revista Românească pentru Educație Multidimensională, 12(1 Sup2), 61-70.

Diachenko, A., Vusyk, H., Bielova, Y., Shurdenko, M., \& Titenko, O. (2021). The educational role in COVID-19 terms of ethnodesign graphic function in higher education practical activities. International Journal of Health Sciences, 5(3), 584-593. https://doi.org/10.53730/ijhs.v5n3.2540

Dzvinchuk, D., Radchenko, O., Kachmar, O., Myskiv, I., \& Dolinska, N. (2020). Analysis of platforms and tools of open study in the conditions of postmodern education. Revista Romaneasca pentru Educatie Multidimensionala, 12(3), 125-143.

Ernawati, E., Baso, Y. S., Hidayanty, H., Syarif, S., Aminuddin, A., \& Bahar, B. (2022). The effects of anemia education using web-based she smart to improve knowledge, attitudes, and practice in adolescent girls. International Journal of Health \& Medical Sciences, 5(1), 44-49. https://doi.org/10.21744/ijhms.v5n1.1831

European Commission. (2019). European Commission Country Report Romania.

Gallagher, T. H., \& Schleyer, A. M. (2020). "We signed up for this!"-student and trainee responses to the Covid-19 pandemic. New England Journal of Medicine, 382(25), e96.

Hoofman, J., \& Secord, E. (2021). The effect of COVID-19 on education. Pediatric Clinics, 68(5), 1071-1079.

Kaparounaki, C. K., Patsali, M. E., Mousa, D. P. V., Papadopoulou, E. V., Papadopoulou, K. K., \& Fountoulakis, K. N. (2020). University students' mental health amidst the COVID-19 quarantine in Greece. Psychiatry research, 290, 113111. https://doi.org/10.1016/j.psychres.2020.113111

Kliuchnyk, A., Shebanin, V., Shebanina, O., Kormyshkin, Y., Rybachuk, V., \& Buryk, Z. (2021). Strategic Factors Quality Of Public Administration In Regional Development: The Experience Of Eu Countries. International Journal for Quality Research, 15(4), 1317. 
Kostikova, I., Miasoiedova, S., Razumenko, T., Chernenko, A., \& Pochuieva, O. (2019). Teaching English speaking for fce: using facebook as a tool of instructional practice. Amazonia investiga, 8(22), 719-727.

Kuzmina, M. O., Protas, O. L., Fartushok, T. V., Raievska, Y. M., \& Ivanova, I. B. (2020). Formation of students' competence of tertiary educational institutions by practical training aids.

Lee, J., Hong, N. L., \& Ling, N. L. (2001). An analysis of students' preparation for the virtual learning environment. The internet and higher education, 4(3-4), 231-242. https://doi.org/10.1016/S10967516(01)00063-X

Mattison, R. E., Hooper, S. R., \& Glassberg, L. A. (2002). Three-year course of learning disorders in special education students classified as behavioral disorder. Journal of the American Academy of Child \& Adolescent Psychiatry, 41(12), 1454-1461. https://doi.org/10.1097/00004583-200212000-00017

Mukhtar, A. U. S., Budu, B., Sanusi B, Y., Mappawere, N. A., \& Azniah, A. (2022). The effect of reproductive health education with multimedia video learning on the improvement of fluor albus prevention behavior young woman pathologist. International Journal of Health \& Medical Sciences, 5(1), 75-79. https://doi.org/10.21744/ijhms.v5n1.1841

Oster, E., Jack, R., Halloran, C., Schoof, J., McLeod, D., Yang, H. ... \& Roche, D. (2021). Disparities in learning mode access among K-12 students during the COVID-19 pandemic, by race/ethnicity, geography, and grade level-United States, September 2020-April 2021. Morbidity and Mortality Weekly Report, 70(26), 953.

Palmer, R. F., Blanchard, S., Stein, Z., Mandell, D., \& Miller, C. (2006). Environmental mercury release, special education rates, and autism disorder: an ecological study of Texas. Health \& Place,12(2), 203-209. https://doi.org/10.1016/j.healthplace.2004.11.005

Powers, L. E., Geenen, S., Powers, J., Pommier-Satya, S., Turner, A., Dalton, L. D., ... \& Swank, P. (2012). My Life: Effects of a longitudinal, randomized study of self-determination enhancement on the transition outcomes of youth in foster care and special education. Children and Youth Services Review, 34(11), 2179-2187. https://doi.org/10.1016/j.childyouth.2012.07.018

Rababah, I. H. M. (2020). The reality of using modern teaching methods in teaching Arabic for speakers of other languages from teachers' perspective. Journal of Social Sciences (COES\&RJ-JSS), 9(1), 58-94.

Riva, G., Wiederhold, B. K., \& Mantovani, F. (2021). Surviving COVID-19: the neuroscience of smart working and distance learning. Cyberpsychology, Behavior, and Social Networking, 24(2), 79-85.

Rose, S. (2020). Medical student education in the time of COVID-19. Jama, 323(21), 2131-2132.

Singh, S., Roy, D., Sinha, K., Parveen, S., Sharma, G., \& Joshi, G. (2020). Impact of COVID-19 and lockdown on mental health of children and adolescents: A narrative review with recommendations. Psychiatry research, 293, 113429. https://doi.org/10.1016/j.psychres.2020.113429

Slipchuk, V., Yuzkiv, H., Batechko, N., Pisotska, M., \& Klymenko, L. (2021). Academic mobility development among university students during COVID-19 pandemic. International Journal of Health Sciences, 5(3), 573583. https://doi.org/10.53730/ijhs.v5n3.2490

Synorub, H., \& Medynska, O. (2019) Development of information culture of students of humanitarian specialities. Information Technologies and Learning Tools, 72(4), 152-167.

Van de Groep, S., Zanolie, K., Green, K. H., Sweijen, S. W., \& Crone, E. A. (2020). A daily diary study on adolescents' mood, empathy, and prosocial behavior during the COVID-19 pandemic. PloS one, 15(10), e0240349.

Viswanathan, R., Myers, M. F., \& Fanous, A. H. (2020). Support groups and individual mental health care via video conferencing for frontline clinicians during the COVID-19 pandemic. Psychosomatics, 61(5), 538-543. https://doi.org/10.1016/j.psym.2020.06.014

Widana, I.K., Sumetri, N.W., Sutapa, I.K., Suryasa, W. (2021). Anthropometric measures for better cardiovascular and musculoskeletal health. Computer Applications in Engineering Education, 29(3), 550561. https://doi.org/10.1002/cae.22202

Zhernova, A. (2018). Information and communication technologies in higher education: toward the preparedness of the subjects of education for innovation. Scientific Research in Social and Political Psychology, 33, 172-179.

Marynets, N., Marynchenko, H., Vynnychuk, R., Voloshchuk, H., \& Voropayeva, T. (2022). Education of humanitarian specialists during COVID-19 pandemic. International Journal of Health Sciences, 6(1), 244-254. https://doi.org/10.53730/ijhs.v6n1.3907 


\section{Biography of Authors}

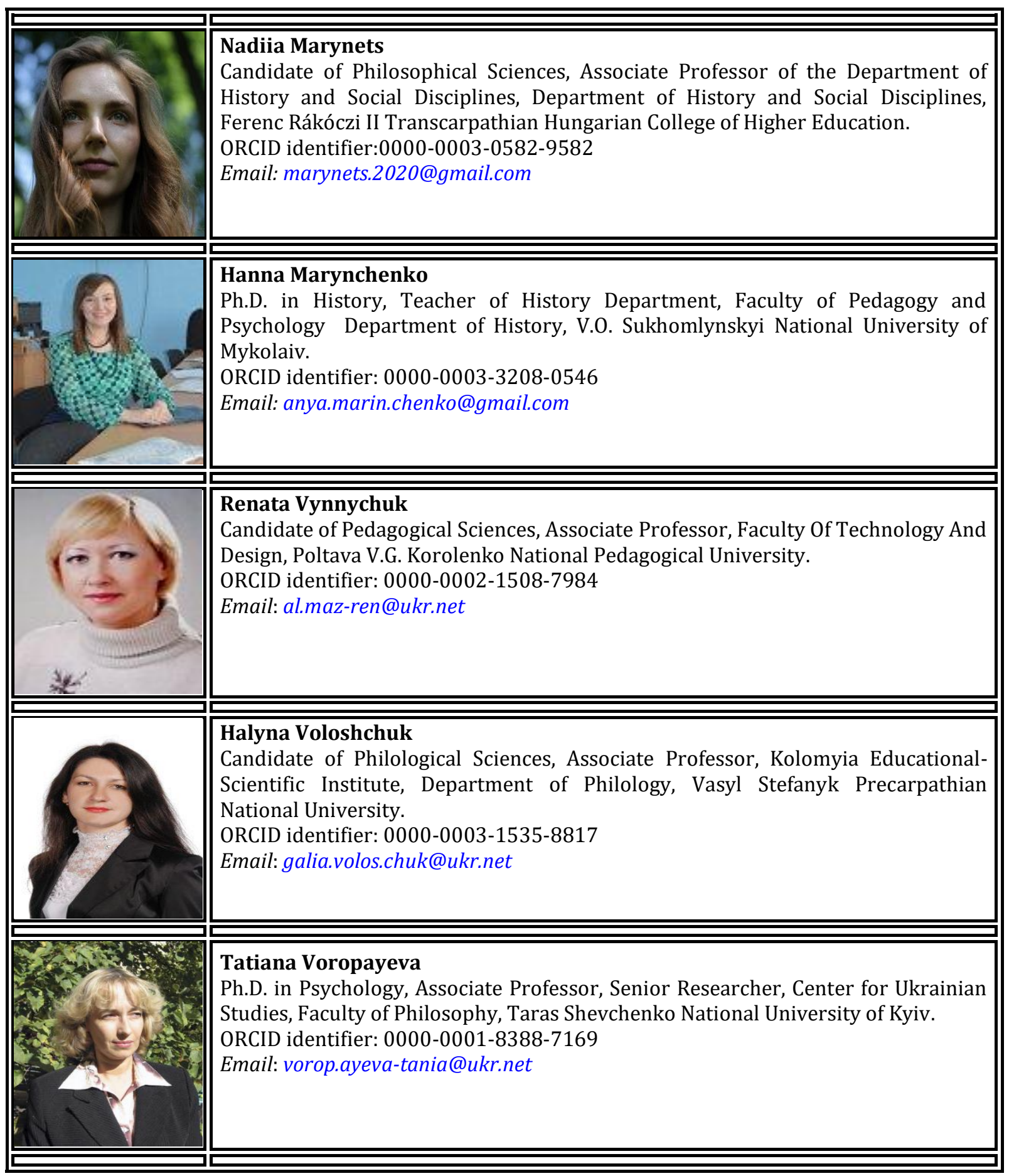

